\title{
Green morays (Gymnothorax funebris) have sedentary ways in mangrove bays, but also ontogenetic forays to reef enclaves
}

\author{
Matthew S. Kendall • Laughlin Siceloff • Ashley Ruffo • Arliss Winship • \\ Mark E. Monaco
}

Received: 11 March 2021 / Accepted: 4 August 2021 / Published online: 11 August 2021

This is a U.S. government work and not under copyright protection in the U.S.; foreign copyright protection may apply 2021

\begin{abstract}
Surprisingly, little is known about basic life history of the largest moray eel species in the Caribbean region, the green moray eel (Gymnothorax funebris). Sixteen eels were captured from the mangrove fringe in multiple bays on St. Croix, USVI, implanted with coded acoustic transmitters, and their movements were tracked for up to 11 months using an array of 37 stationary acoustic receivers. They exhibited high site fidelity in the bays during their residence, using the same general parts of individual bays and did not switch bays except for one individual. There was no relationship between eel size (mean $\mathrm{TL}=83 \mathrm{~cm}$, range $=54-126 \mathrm{~cm}$ ) and home range size (mean area of $95 \% \mathrm{KUD}=5.8$ ha \pm 0.7 SE). Most individuals were more frequently detected at night than during the day suggesting greater nocturnal activity. Several of the larger eels (mean
\end{abstract}

M. S. Kendall $(\bowtie) \cdot$ L. Siceloff · A. Winship ·

M. E. Monaco

National Oceanic and Atmospheric Administration/NOS/

NCCOS/MSE/Biogeography Branch, 1305 East West

Highway, Silver Spring, MD 20910, USA

e-mail: matt.kendall@noaa.gov

L. Siceloff · A. Winship

CSS Inc., 10301 Democracy Lane, Suite 300, Fairfax,

VA 22030, USA

A. Ruffo

ERT Inc., NOAA National Marine Fisheries

Service, 3013 Estate Golden Rock, Christiansted,

US Virgin Islands 00820, USA
$\mathrm{TL}=93 \mathrm{~cm} \pm 5.9 \mathrm{SE}$ ) showed clear and permanent emigration tracks out of the mangrove estuary to coral reef habitats offshore. For some individuals, these habitat shifts were preceded by exploratory movements away from the eel's typical home range the night before emigration. All final emigration events took place nocturnally, happened during a single night, and occurred during months from December to May. Mean emigration speed was $3.4 \mathrm{~km} / \mathrm{h}$. This study is the first documentation of an ontogenetic habitat shift in moray eels, as well as the first determination of home range size for this species and their site fidelity in mangrove habitats.

Keywords Acoustic telemetry $\cdot$ Home range · Emigration $\cdot$ Nursery habitat $\cdot$ Caribbean

\section{Introduction}

Moray eels are more abundant than generally realized and are an important component of many marine ecosystems. Due to their habit of hiding in holes and crevices, and their often nocturnally active nature, they are undercounted on single-pass visual surveys by as much as $400 \%$ (Gilbert et al. 2005). In terms of biomass, they are possibly as important as other piscivores such as snapper and grouper, and may be increasing in absolute or relative abundance since the others are targets of fisheries whereas morays are typically not due to ciguatoxicity (Gilbert et al. 
2005; Chan 2017; Kendall et al. 2021a). Moray eels play a unique role in structuring fish communities in complex habitats due to their characteristic ability to navigate rock crevices, reef holes, mangrove roots, and other three-dimensional structures (Parrish et al. 1986; Hixon and Beets 1993; Higgins and Mehta 2018). They form cooperative foraging associations with other piscivores seeking to exploit moray eels' physical capabilities of flushing prey from holes (Abrams et al. 1983; Santos and Castro 2003; Vail et al. 2013; Aschenbrenner and Marques 2018). Morays also have a special allure to recreational scuba divers with their fearsome dentition, protractible pharyngeal jaws, and reputation as dangerous marine life (Mehta and Wainwright 2008; Harrison et al. 2017). Despite these intriguing characteristics, surprisingly little is known about basic aspects of life history for most moray species.

Shelter fidelity and movement has been investigated for a few species of moray eel using field observations and telemetry. Daily visual surveys for 2 months in summer (Abrams et al. 1983) and winter (Young and Winn 2003) revealed sheltering habits for three Caribbean species. Individual spotted (G. moringa), and purplemouth morays (G. vicinus) used the same reef hole for days to weeks before shifting to a new location a short distance away $(<25 \mathrm{~m})$. Goldentail morays ( $G$. miliaris) had greater shelter fidelity and remained in the same hole for 1-2 months. Telemetry of four spotted and one purplemouth moray tracked for six days showed maximum nocturnal forays of 90 to $115 \mathrm{~m}$ from shelter sites, primarily into nearby seagrass (Young and Winn 2003). In other systems, mark-recapture of 462 California morays (G. mordax) conducted over 2 years recaptured 170 individuals, all of which were at their original trapping sites and did not move between adjacent coves just $100 \mathrm{~m}$ apart (Higgins and Mehta 2018). Mediterranean morays (Muraena helena) tracked using telemetry during summer months off Portugal $(n=19)$ revealed a 19.4 ha home range (Pereira et al. 2017). A discontinuous telemetry study of 5 yellow moray eels (G. prasinus) over 10 months in New Zealand demonstrated that eels use a consistent general area ( 0.15 to 1 ha) but not the same hole day to day (Bassett and Montgomery 2011). Collectively, these studies indicate that moray eels have a high degree of fidelity to general locations although their particular shelter hole can vary on the scales of days to months depending on the species.

While these previous studies have resulted in key insights into the habits of moray eel species, many were conducted over short durations (i.e., days to single seasons), are based on small sample size (i.e., a few individuals), or cover limited geographic scope (i.e., one habitat type). This has resulted in a piecemeal understanding of their habitat utilization patterns over longer timescales and multiple habitats. For example, by focusing on single habitats and seasons in reef systems, whether juveniles use the same habitats as adults or if, like many reef fish, they undergo an ontogenetic shift in ecosystem location or role, is unknown (Cocheret de la Morinière et al. 2003; Aburto-Oropeza et al. 2009; Luo et al. 2009; Huijbers et al. 2015).

The green moray (Gymnothorax funebris) is especially poorly known apart from general life history information despite it being the largest moray eel in the tropical Atlantic Ocean with a maximum total length of $2.5 \mathrm{~m}$ and weight of $30 \mathrm{~kg}$ (Robins and Ray 1986). Green morays are typically found solitarily on highly rugose coral reef habitats of the Caribbean Sea in waters shallower than $30 \mathrm{~m}$ deep, but their range extends along the western Atlantic northward to New Jersey and southward including coastal waters of northern Brazil (Robins and Ray 1986). They are a common, although not abundant, reef dweller that are also known to occur in mangroves (Aschenbrenner and Marques 2018). Their diet is composed primarily of fish, crustaceans, and other reef fauna (Randall 1967). Apart from these basic facts, little else is known about green morays including site fidelity, home range size, habitat shifts, or migrations.

We addressed this knowledge gap using acoustic telemetry wherein uniquely coded transmitters are implanted into the body cavities of subject eels and acoustic data loggers (hereafter "receivers") are used to monitor their movements throughout an ecosystem. An array of receivers were strategically placed in multiple mangrove-lined bays as well as coral reef habitats offshore to monitor eel movements for 11 months. The objectives of the study were to document temporal and spatial aspects of green moray's occupancy of mangrove bays. Specifically, we quantify overall home range and core area size, site fidelity within bays, activity patterns during day vs. night, and document emigration/ontogenetic shift events 
from mangroves to the reefs offshore including pathway, speed, and timing.

\section{Materials and methods}

Study area

Salt River Bay National Historical Park and Ecological Preserve lies on the north central coast of St.Croix, US Virgin Islands (Fig. 1). The estuary is comprised of four smaller bays that lead into a common central basin which is open to the ocean through a natural cut in a fringing reef at the head of the underwater Salt River Canyon (Kendall et al. 2005). The canyon has steep sides with many caves and overhangs and is flanked by flat carbonate pavement to the east and west. All four of the estuary's bays are 2-4 $\mathrm{m}$ deep, have a mud or sandy bottom, sparse algae or seagrass, and apart from the seawall portion of the marina, all four are lined with red mangroves (Rhizophora mangle). Salt River Bay's central basin is deeper $(\sim 5 \mathrm{~m})$, has a sandier bottom, greater seagrass and algae coverage, occasional hardbottom, and a shoreline consisting of sand, rocks, coral rubble, or isolated mangroves.

Temperature (27-29 C) and salinity (35-36 PPT) are similar throughout these bays except during times
Fig. 1 Salt River Bay study area with site numbers of VR2W telemetry receivers. Rectangle in the inset shows location of Salt River Bay on north coast of St.Croix. $\mathrm{CSO}=$ National Park Service's Coastal Studies Outpost where field operations were staged

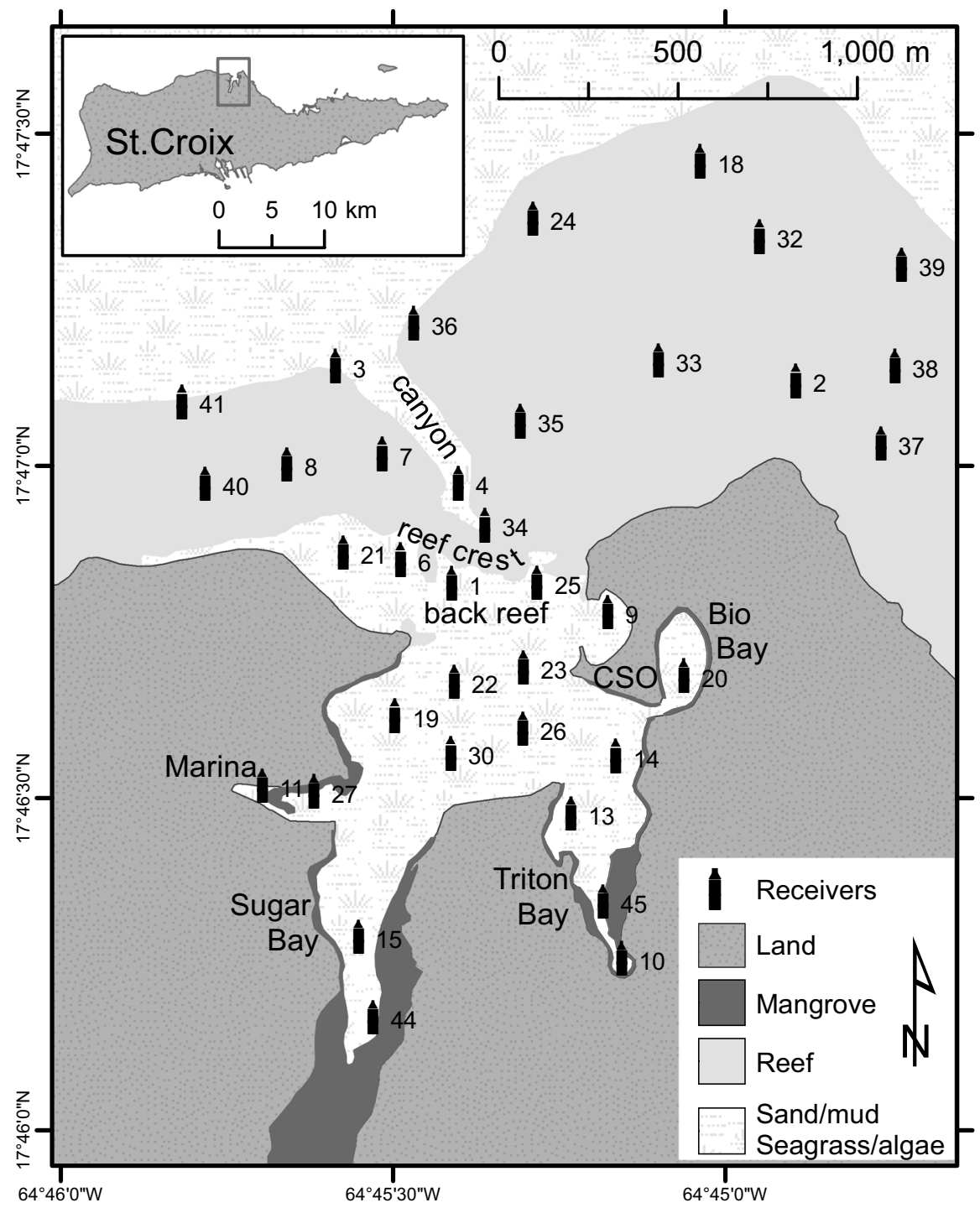


of heavy rainfall when Sugar Bay receives runoff from its large watershed which can reduce salinity on a temporary basis (Kendall et al. 2005). Average oxygen saturation is lowest in the extremities of the bays (65-69\%) compared to locations closer to the reef cut (81-84\%), whereas turbidity is highest far inside the bays (3-5 nephelometric turbidity units or NTU) compared to the central basin (1-3 NTU) (Kendall et al. 2005).

Fish tagging and tracking

On multiple field missions from July to November 2018, green morays were live captured using fish traps deployed along the mangrove fringe in Sugar, Triton, and Bio Bay (Table 1). Trap deployment areas along the mangroves, bait (frozen local herring), and specifications (1.3 cm vinyl-coated wire mesh, $92 \times 57 \times 19 \mathrm{~cm}$, funnel opening $9 \mathrm{~cm}$ diameter) were generally dictated by a long term study of juvenile fishes in the area (Kendall et al. 2021a). Most eels were trapped in the bay; the one exception was taken by a larger mesh trap outside the reef crest near receiver 8 (Fig. 1). Trapped eels were placed into shaded bins filled with local bay-water. All eels were well above the minimum weight recommended to accommodate the transmitters $(<2 \%$ of body weight) and were tagged. Eels were anaesthetized using $300 \mathrm{ppm}$ tricaine methanesulfonate (MS-222) and total length was measured. Coded acoustic transmitters (VEMCO model V8-4L, random ping delay 130-230 s, 324 day battery life) were implanted into the body cavity through a $1.5 \mathrm{~cm}$ ventral incision using well established surgical practices for other species of moray eels (Basset and Montgomery 2011; Pereira et al. 2017). After the 1-2-min surgical procedure, tagged individuals were moved to a separate recovery bin until normal respiratory and swimming behaviors resumed, and then were released at the point of capture.

Thirty-seven acoustic receivers (VEMCO, VR2W) were strategically placed throughout the bays and extending offshore into a submarine canyon and coral reef habitats as part of a general fish telemetry study ( $n=19$ inside the estuary, $n=18$ outside the fringing reef) (Kendall et al. 2021b) (Fig. 1). Receivers were spaced approximately evenly in a tiered arrangement from the smaller bays, central bay, back reef, and offshore to detect eel passage (200 - $250 \mathrm{~m}$ apart inside the bays and canyon). Detection range tests and a sentinel tag were used to monitor temporal changes in detections due to environmental factors and aid

Table 1 Tagging and detection summary for each eel. DD denotes detection days; RI is residence index. Eels are in order of tagging location and then eel ID. Array was decommissioned June 24, 2019

\begin{tabular}{llllllll}
\hline Eel ID & Length $(\mathrm{cm})$ & Tagging location & Release date & Last detection & $\begin{array}{l}\text { Track span } \\
\text { (days) }\end{array}$ & DD & RI (DD/span) \\
\hline GF13 & 82 & Sugar Bay & $09 / 06 / 2018$ & $06 / 05 / 2019$ & 272 & 218 & 0.80 \\
GF36 & 83 & Sugar Bay & $09 / 06 / 2018$ & $01 / 19 / 2019$ & 135 & 115 & 0.85 \\
GF44 & 88 & Sugar Bay & $07 / 25 / 2018$ & $05 / 30 / 2019$ & 309 & 208 & 0.67 \\
GF49 & 72 & Sugar Bay & $11 / 07 / 2018$ & $06 / 20 / 2019$ & 225 & 213 & 0.95 \\
GF54 & 90 & Sugar Bay & $11 / 07 / 2018$ & $02 / 20 / 2019$ & 105 & 105 & 1.00 \\
GF72 & 85 & Sugar Bay & $09 / 06 / 2018$ & $06 / 18 / 2019$ & 285 & 198 & 0.70 \\
GF15 & 83 & Triton Bay & $07 / 26 / 2018$ & $06 / 18 / 2019$ & 327 & 230 & 0.70 \\
GF21 & 65 & Triton Bay & $09 / 05 / 2018$ & $06 / 06 / 2019$ & 274 & 12 & 0.04 \\
GF37 & 69 & Triton Bay & $11 / 06 / 2018$ & $06 / 24 / 2019$ & 230 & 224 & 0.97 \\
GF46 & 90 & Triton Bay & $11 / 06 / 2018$ & $06 / 24 / 2019$ & 230 & 225 & 0.98 \\
GF63 & 99 & Triton Bay & $07 / 26 / 2018$ & $12 / 29 / 2018$ & 156 & 147 & 0.94 \\
GF64 & 96 & Triton Bay & $07 / 26 / 2018$ & $06 / 23 / 2019$ & 332 & 290 & 0.87 \\
GF30 & 54 & Bio Bay & $11 / 08 / 2018$ & $06 / 03 / 2019$ & 207 & 168 & 0.81 \\
GF47 & 58 & Bio Bay & $09 / 05 / 2018$ & $06 / 11 / 2019$ & 279 & 157 & 0.56 \\
GF70 & 83 & Central Bay & $11 / 08 / 2018$ & $01 / 04 / 2019$ & 57 & 18 & 0.31 \\
GF14 & 126 & Reef & $07 / 26 / 2018$ & $08 / 31 / 2018$ & 36 & 14 & 0.39 \\
\hline
\end{tabular}


with interpretation of detections from eels. Those data were evaluated in a previous study (Kendall et al. $2021 \mathrm{~b}$ ) and revealed the $50 \%$ probability of detection to be $\sim 200 \mathrm{~m}$ which indicates that our array spacing enabled monitoring of most bay areas. The sentinel tag was detected every day in 2018 and there was no difference in day versus night detections. This makes accounting for seasonal or diel bias during analysis unnecessary (Kendall et al. 2021b). Receivers were retrieved, cleaned, and downloaded every 6 months. The array was removed on June 24, 2019.

\section{Analysis}

Data were formatted and organized through the Florida Atlantic Coast Telemetry Network (Young et al. 2020) and the glatos package in $\mathrm{R}$ (Krueger et al. 2017). A residency index (RI) was used to determine the proportion of time that each eel was tracked within the acoustic array overall. This was calculated by dividing the total number of detection days (i.e., a day with a detection anyplace in the array) by the transmitter lifespan (release date to final detection date). The percentage of all detections that occurred at each receiver during the day versus night were expressed as stacked bar graphs for each eel. For the purposes of this study, day was defined as 6:15 AM-6:15 PM local time, and night was defined as 6:15 PM-6:15 AM based on average time of sunrise and sunset at this latitude where day length is $\sim 12 \mathrm{~h} \pm 1$ all year.

Spatial and temporal detection patterns within bays

The potential influence of time of day on detection patterns was examined using a chi-square goodness of fit test (Zar 1999). Specifically, we evaluated if eels were detected more during the day or night since studies among moray eel species have shown different patterns in diel activity. For this analysis, we summarized the number of detections by time of day (i.e., daytime vs. nighttime) for each fish and tested the null hypothesis that detections had an equal distribution during the day vs. night (i.e., 1:1 ratio). Raw numbers of detections were appropriate for comparison in this analysis because both time categories were $12 \mathrm{~h}$ every day and the sentinel tag revealed no difference in the day vs. night detectability due to environmental factors (Kendall et al. 2021b). Thirteen of the 16 eels tagged had over 100 detection days to make for a robust comparison, however 3 (GF14, GF21, and GF70) had less than 20 days available for analysis and were therefore excluded. Bonferroni adjusted $p$ values $(0.05 / 13$ tests $=0.0038)$ were used to account for conducting multiple tests of these 13 fish.

Customized abacus plots were used to visualize monthly and seasonal patterns for each fish. Detection days for each individual were coded by receiver and whether the detection occurred during the daytime, nighttime, or both. All receivers used by eels in each tagging area (e.g., Triton or Sugar Bay) are shown to enable comparisons among their detection patterns.

Preliminary evaluation revealed that there was no increase in number of receivers visited as eels aged (Fig. 2a-c). Therefore, home range was calculated for each eel for their overall detection span (excluding departure tracks for individuals that emigrated). First, centers of activity (CoA) (Simpfendorfer et al. 2002) were determined on hourly time steps using the VTrack package in R (Campbell et al. 2012). Then the Brownian Bridge Kernel Utilization Density (KUD) was calculated from CoA data using the adeHabitatHR package in $\mathrm{R}$ (Calenge 2006). Last, the 95\% activity volume contour of the KUD was clipped using a land polygon to determine the submerged area inside the contour. This value was reported as the overall home range of each eel. The relationship between home range and eel size was tested using simple linear regression because there was no evidence of non-linear patterns in plots of the data.

\section{Emigration}

In this study, individuals with detections that exhibited a clear exit track out of the bays to the backreef, canyon, or farther offshore and were never detected again were defined as having emigrated in an ontogenetic shift. A Student's $t$-test was used to determine if mean size of eels emigrating was different than that of eels that did not emigrate (Zar 1999). Several aspects of emigration events were investigated in detail. First, their home range, approximated by the 95\% volume contour of their KUD, and the sequence of receivers where they were detected during departure was mapped. Next, average movement speed during emigration was calculated based on the timing of successive detections and the straight line distances between receivers along their exit track. Last, we used binomial tests (Zar 1999) to determine whether 

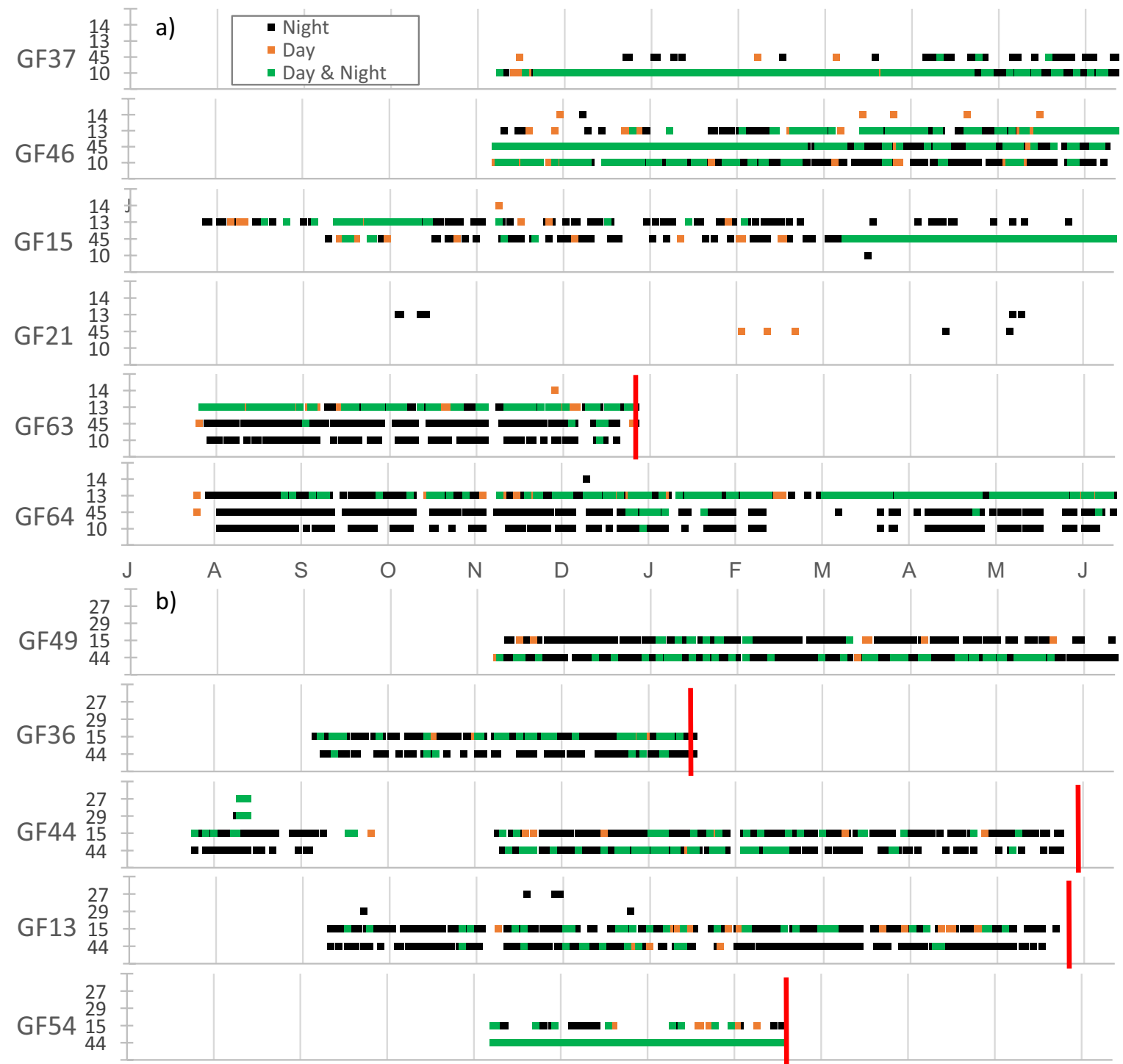

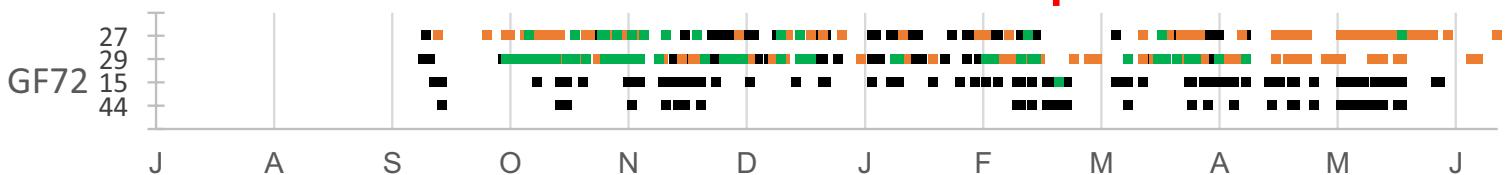

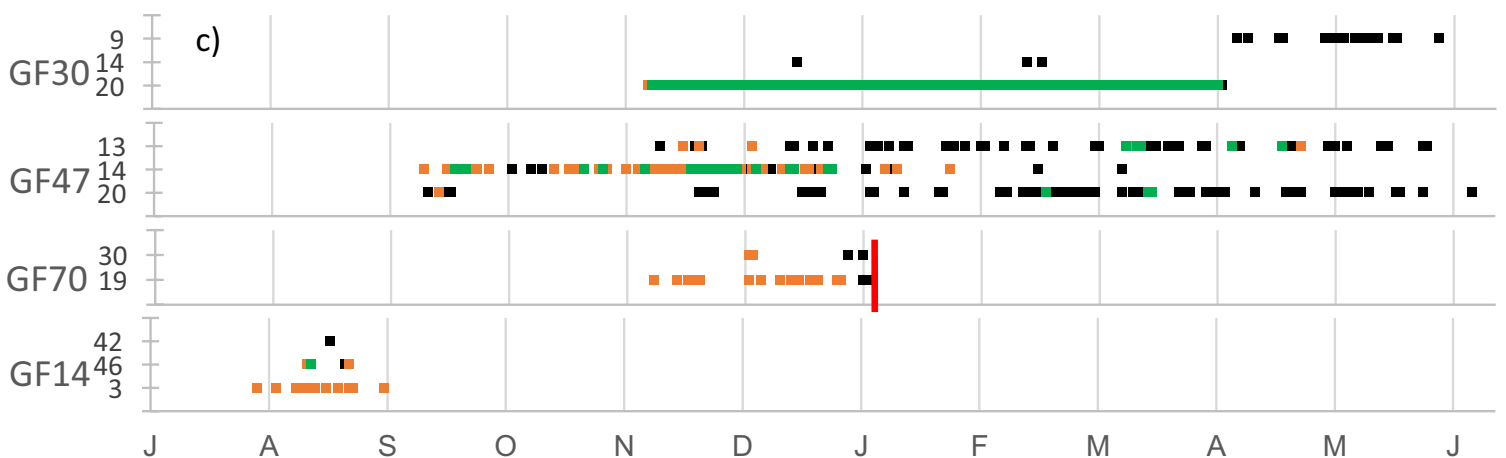


4 Fig. 2 a-c Abacus plots of detection days for eels from: a Sugar Bay, b Triton Bay, and c Bio Bay and other locations by receiver and diel period (day, night, or both). Months are noted along the $X$ axis and receiver station numbers are listed after each eel (GF\#\#) on the $\mathrm{Y}$ axis. When present, a red line indicates dates of eel emigration

emigration occurred randomly during daytime or nighttime, during winter/spring months (Dec-May) or summer/fall (June-Nov), and potential influence of the lunar phase during emigration dates.

\section{Results}

Spatial and temporal detection patterns within bays

Sixteen green morays from multiple locations within the study area were tagged and tracked. These eels provided 1 to 11 months of detection data with an average detection duration of 7.2 months (Table 1). The residency index denoting proportion of days that eels were detected within the array prior to their emigration or the termination of the project ranged from $\mathrm{RI}=0.04$ (GF21 was only detected of $4 \%$ of days over 9 months) to 1.0 (GF54 was detected every day for over 3 months) with an average of 0.72 .

When the number of daytime versus nighttime detections were compared for each eel, all were significantly different $(p<0.001)$ than a random ratio of 1:1 (Table 2). Of the 13 eels with sufficient data to be tested, 10 had a significantly greater number of detections at night, and 3 had a significantly greater number during the day.

Most individuals had very consistent detection patterns during their entire detection span, typically only on 2-3 adjacent receivers throughout their residency in the bays (Fig. 2a-c). Two eels switched from one receiver to an adjacent receiver in Triton Bay as their daytime sites (GF15 and GF46). Three others switched their daytime refuge sites, although exactly where is unclear since daytime detections were present on our receivers and then missing for several weeks for those individuals (GF30, GF47, and GF64). In most cases however, their nighttime detection sites were consistent indicating they were still close by, just in a blind spot in the array such as deep in the prop roots during the day. Eel GF44 was undetectable for several weeks in September and October during both day and nighttime but resumed being detected on its typical receivers in Sugar Bay consistently for the remaining 7 months of its residency. Only one eel switched bays. Eel GF30 resided in Bio Bay for 5 months before switching to the small cove on the other side of the CSO (Fig. 1) for the final 2 months before the array was decommissioned. Three eels had too few detections to enable robust conclusions (GF14, GF21, and GF70), but even these intermittent detections followed a pattern where only $2-3$ receivers were involved. Unfortunately, GF14, the largest eel in the study and the only one tagged outside the bays to begin with, was only detected for a little over a month before disappearing at the northwest edge of the canyon.

Stacked bar graphs of cumulative detections among receivers during daytime versus nighttime reveal that most individuals were detected on the same set of a few receivers during the day and night (GF21, GF46, GF63, GF64, GF13, GF36, GF44, GF72, GF47, and GF14) (Fig. 3a-c). Of note however, the proportions differed during the day versus night for each fish suggesting a small shift in the area used for foraging versus resting. The other individuals had just 1 receiver loaded with the bulk of both daytime and nighttime detections (GF15, GF37, GF49, GF54, GF30, and GF70) suggesting that they forage in the same small general area where they take refuge.

Home range size (95\% KUD) during bay residence was similar among most individual eels except for GF47 and GF72 which had 4 to 5 times larger home range size than the others (Table 2). These two individuals resided in Triton and Sugar bays respectively, but had relatively few CoA positional data which were distributed evenly over a wider range than other tags. This caused their home range calculation to be very large using the Brownian Bridge method. Excluding these two outliers, average home range size was 5.8 ha $( \pm 0.7 \mathrm{SE})$. There was no significant linear relationship between eel size and home range area calculated with, or without, the outliers.

\section{Emigration}

Most eels were either detected consistently from tagging until array removal (i.e., they did not leave the system) or they exhibited a clear departure track out of the bays. The only exceptions being GF21, which was only intermittently detected in Triton 
Table 2 Bold denotes the higher value in daytime versus nighttime detections where a significant difference was found $(p<0.001)$. Due to low numbers of detection days, GF70, GF14, and GF21 were not tested for day versus night differ-

\begin{tabular}{|c|c|c|c|c|c|c|}
\hline Eel ID & Day detections & Night detections & $\begin{array}{l}\text { Home range ( } 95 \% \\
\text { KUD) (ha) }\end{array}$ & $\begin{array}{l}\text { Emigration date } \\
(2019)\end{array}$ & $\begin{array}{l}\text { Emigration lunar } \\
\text { phase }\end{array}$ & $\begin{array}{l}\text { Emigration } \\
\text { speed }(\mathrm{km} / \mathrm{h})\end{array}$ \\
\hline GF13 & 196 & 1837 & 6.8 & 28 May & Wane & 6.1 \\
\hline GF36 & 159 & 1282 & 6.6 & 19 Jan & Full & 0.9 \\
\hline GF44 & 2249 & 2785 & 7.3 & 30 May & Wane & 4.8 \\
\hline GF49 & 700 & 5447 & 6.0 & - & - & - \\
\hline GF54 & 6608 & 3828 & 2.3 & $20 \mathrm{Feb}$ & Full & 1.4 \\
\hline GF72 & 721 & 929 & 29.5 & - & - & - \\
\hline GF15 & 12,850 & 7133 & 6.8 & - & - & - \\
\hline GF21 & 13 & 10 & - & - & - & - \\
\hline GF37 & 2407 & 8595 & 0.7 & - & - & - \\
\hline GF46 & 13,089 & 22,870 & 6.0 & - & - & - \\
\hline GF63 & 1618 & 6432 & 8.0 & $29 \mathrm{Dec}$ & Wane & 0.6 \\
\hline GF64 & 4898 & 13,253 & 7.4 & - & - & - \\
\hline GF30 & 21,903 & 11,288 & 5.8 & - & - & - \\
\hline GF47 & 435 & 1124 & 36.9 & - & - & - \\
\hline GF70 & 258 & 21 & - & 4 Jan & New & 6.3 \\
\hline GF14 & 27 & 21 & - & - & - & - \\
\hline
\end{tabular}

ences or subject to home range size calculations. Hyphens (-) denote irrelevant columns for eels that did not emigrate or had too few detection days for home range calculations
Bay, and GF14, the largest eel that we tagged, which was already out on the reef at the time of tagging. Six out of the 16 eels showed a clear track of emigration from the bays to the highly rugose environment of the back reef, canyon, or beyond, and then were almost never detected again (Fig. 4a-f). Emigration pathways included one or more detections on at least 5 receivers outside an eel's core area, with the exception of GF63 which was only detected on one backreef receiver during its exit (Fig. 4e). There was little variation in each individuals' typical pattern of daily detections leading up to the abrupt departure. Emigrations typically occurred in just one night although two eels (GF36 and GF70) demonstrated movements that were different from their typical daily patterns on the night before their final departure and partly matched the pathway of their emigration. One of those (GF70) even went beyond the reef crest into the canyon before returning to its core area the night before its final emigration. Departing eels were all greater than $82 \mathrm{~cm} \mathrm{TL}$ although not all eels that large emigrated during the monitoring period (i.e., GF15, GF46, and GF64 were 83 to $96 \mathrm{~cm}$ TL). Mean length of eels that emigrated $(93 \mathrm{~cm} \pm 5.9 \mathrm{SE})$ was significantly longer than those that did not $(75 \pm 4.9 \mathrm{SE})$ (Student's $t$, $p=0.03$ ).

When eels left the bays, all 6 did so at night which is significantly different from random (binomial test, $p=0.016$ ). All departures began after sunset, ranging from 7:34 PM to 3:14 AM local time. The last detection of emigration events was always before dawn the same night of departure, ranging from 8:33 PM to $5: 25 \mathrm{AM}$. Speed of emigration ranged from 0.6 to $6.3 \mathrm{~km} / \mathrm{h}$ (Table 2) $($ mean $=3.4 \mathrm{~km} / \mathrm{h})$. Final detections of emigration almost always occurred the same night of departure, after which the emigrants were never detected again. The notable exception was GF13, which was detected just once along the lower forereef east of the canyon, 8 days after departure. All departures occurred in months from December to May (binomial test, $p=0.016$ ). There was no consistent lunar phase among emigrating eels (Table 2).

\section{Discussion}

In this study, we document a previously undescribed ontogenetic habitat shift in moray eels in general, and the home range of green morays in particular. An 
Fig. 3 a-c Percentage of all detections for each eel among receivers calculated during the day and night respectively in: a Triton Bay, b Sugar Bay, and c Bio Bay and others. Any station that comprised $<1 \%$ of a tag's detections for a given period was excluded

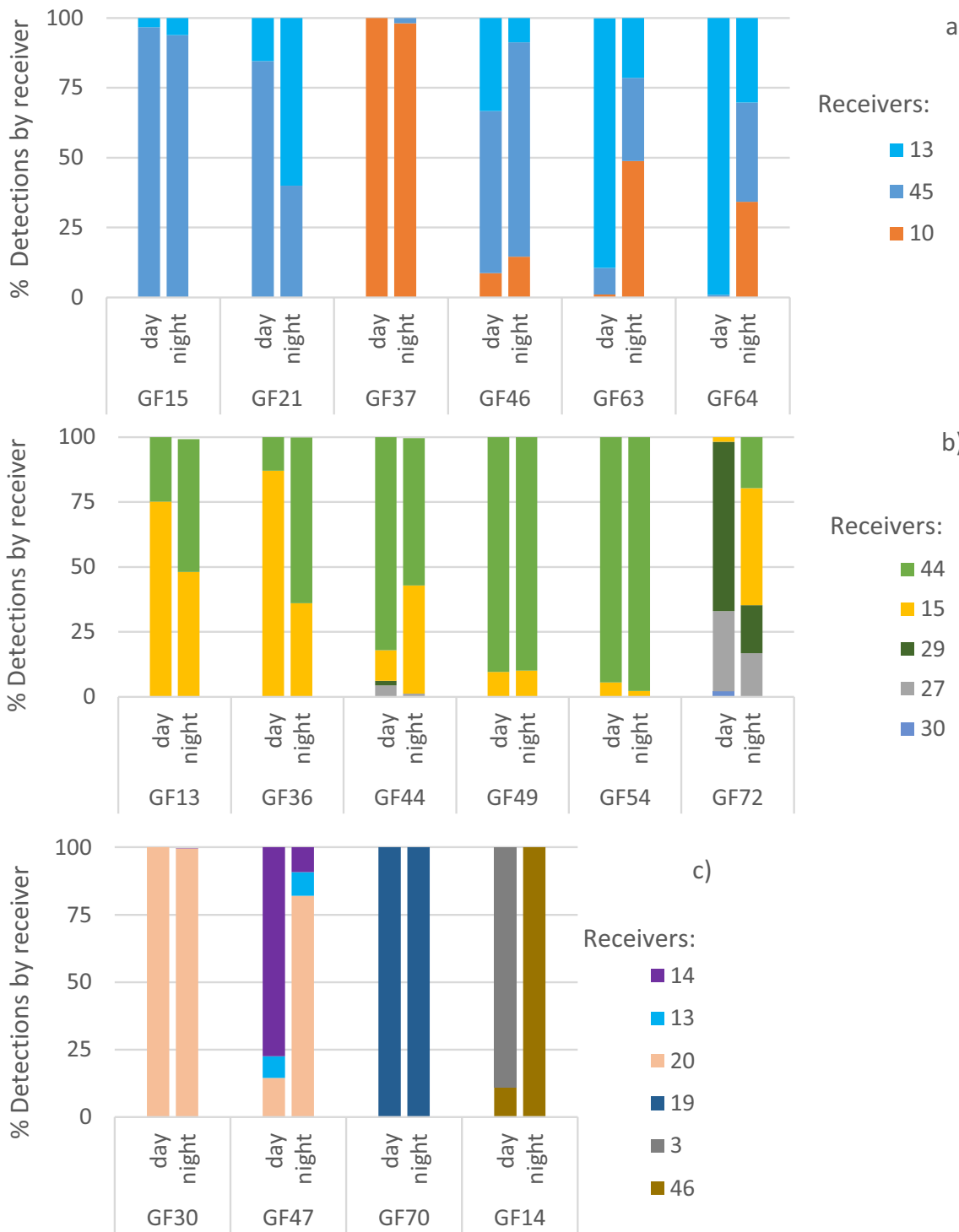

a)

b) extensive acoustic telemetry array was used in a mangrove and reef ecosystem to quantify temporal and spatial movements of green morays over 11 months. Specifically, we quantified diel activity patterns, overall home range and core area size, site fidelity within bays, and emigration/ontogenetic shift events from mangroves to the reefs offshore including pathway, speed, and timing.

Based on the pattern of detections observed here, we suspect that green moray eels in mangroves are more active nocturnally than diurnally. Of the 13 eels with sufficient data to be tested, 10 had a significantly greater number of detections at night, and 3 had a significantly greater number during the day. Because the sentinel tag showed no difference in diel patterns, the greater number of eel detections at night may be due to eels' greater emergence from sound absorbing refugia (i.e., mangrove prop roots encrusted with sessile biota) during nocturnal activities like foraging. The few individuals that were detected more during the day may have had a daytime resting location that happened to be in close proximity to a receiver, thereby enabling easier detection, or they may have actually been more active diurnally. Differences in which receivers detected fish during the day versus night suggest that some green morays use 


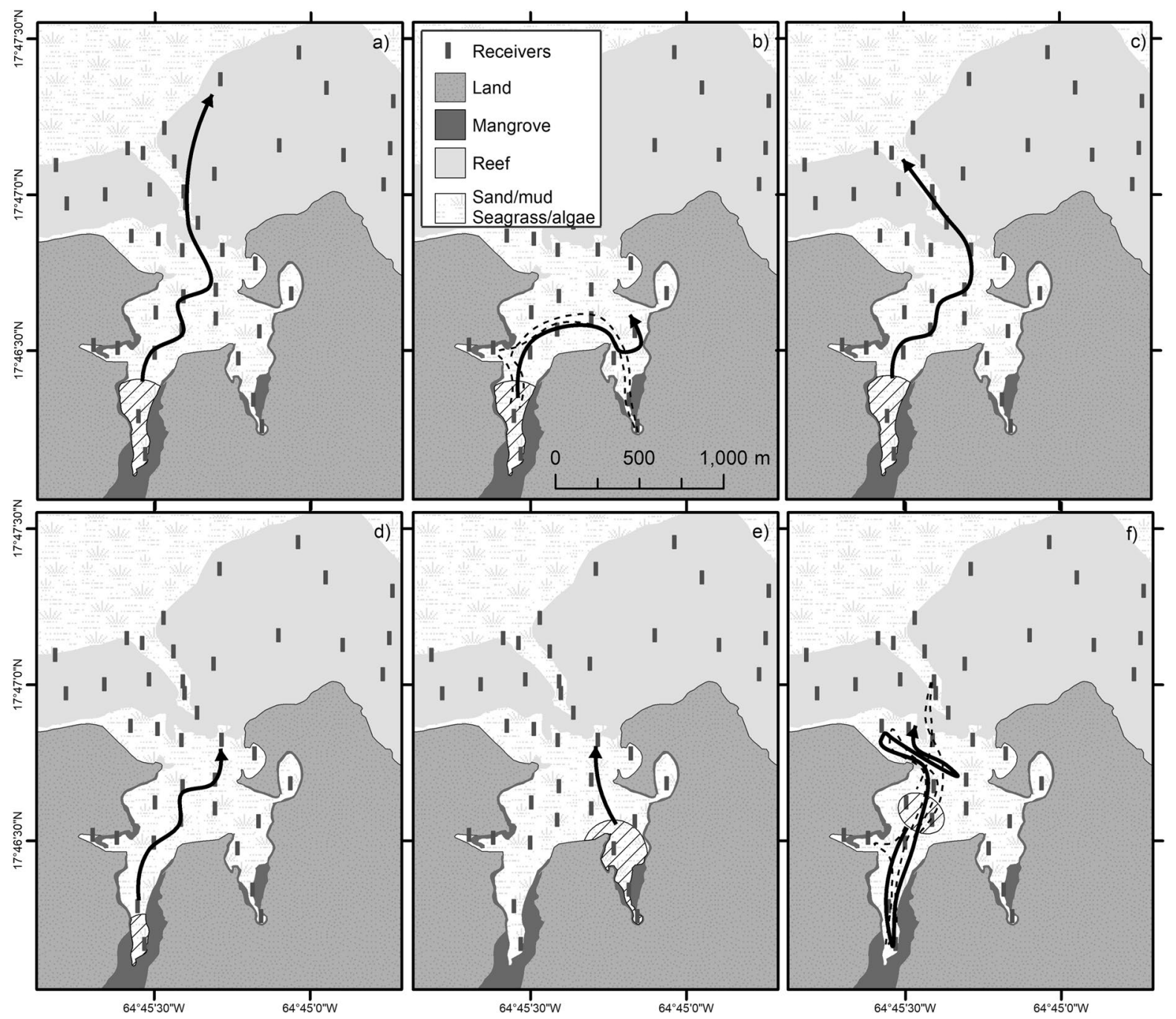

Fig. 4 a-f Location of the receivers where eels resided in the bays $(95 \% \mathrm{KUD}=$ hashed area) and the track of emigration (solid line) for: a GF13, b GF36, c GF44, d GF54, e GF63, and f GF70. Thin dashed line for GF36 and GF70 represents

the same space during both the daytime and nighttime, whereas others use slightly different space, but still in the same bay and on adjacent receivers. This could also be due to a small change in exposure to one receiver or another as they become more active at night. Most moray species are thought to be nocturnal (Young and Winn 2003; Gilbert et al. 2005; Bassett and Montgomery 2011; Pereira et al. 2017; Higgins and Mehta 2018) though there are diurnal exceptions (Abrams et al. 1983; Gilbert et al. 2005), and species with flexible diel cycles (Gilbert et al. 2005). As the track of movements the night prior to emigration. Note that movement lines do not represent actual eel coordinates, only general connections between receivers with consecutive detections for each eel

for green morays, a large majority in our study were night active, but a few had more diurnal detections and indeed, they have been observed foraging during daytime in other mangrove areas (Aschenbrenner and Marques 2018).

Home range size for green morays during mangrove residence was independent of eel length and was broadly consistent among individuals (5.8 ha $\pm 0.7 \mathrm{SE}$ ). This is similar to the yellow moray, G. prasinus ( 0.2 to $10 \mathrm{ha}$ ) (Bassett and Montgomery 2011) but smaller than Mediterranean moray 
(M. helena) (19.4 ha) (Pereira et al. 2017), although comparisons must be interpreted cautiously due to small sample size (Bassett and Montgomery 2011), tracking duration (Pereira et al. 2017), and different habitat types. For example, the Mediterranean and yellow morays are both temperate species that occupy rocky habitat, whereas the green morays in this study were in tropical mangrove habitat. Home range size estimates in mangroves may be especially difficult to interpret because the eels may only be using the mangrove fringe, and seldom move into the open mud and algae bottom away from the prop roots that are included in the KUD area estimates. In addition, whereas these small home range sizes suggest strong fidelity to a particular area, how long eels may occupy the same shelter hole is unknown. Several eels in this study showed subtle shifts in their distribution of detections between adjacent receivers within their home ranges over time. Variability in detections within the home range suggests eels may regularly move among holes (Bassett and Montgomery 2011). More detailed position data will be needed to resolve such fine-scale habitat use.

Ontogenetic habitat shifts are common for many fish species in tropical seascapes wherein primarily juveniles occur in mangroves and adult conspecifics occur on nearby coral reefs (Cocheret de la Morinièr et al. 2003; Aburto-Oropeza et al. 2009; Huijbers et al. 2015). Several of the larger eels in our study exhibited a distinct habitat shift from the mangroves to the reef which ended our detection of them in the array. During their emigration, eels were detected only once or twice on receivers along their exit route. This low detectability occurred despite distances and movement speeds that would have allowed a potentially much larger number of detections given the ping interval of the transmitters (i.e., random delay between 130 and $230 \mathrm{~s}$ ). This suggests that eel emigration occurred along the bottom and through habitats known to muffle transmissions such as thick seagrass or moving from structure to structure (e.g., isolated rocks, sand blowouts, or depressions) (Swadling et al. 2020). For perspective, note that mean emigration speed for eels estimated here $(3.4 \mathrm{~km} / \mathrm{h})$, is roughly equivalent to a slow walking pace for humans. This would seem to enable a methodical but steady passage away from an eel's core area through unexplored areas rather than a sudden dash. Of note however, this estimate is based on straight line distances between receivers and rare detection events, whereas in reality, actual pathways of eels could be more circuitous (longer) between receivers. Similarly, this estimate does not account for receiver range and the impossibility of knowing where an individual actually is within the monitored area, although this is less of a concern as eels move along a line of multiple receivers. The only other study to estimate moray movement speed using telemetry is for the Mediterranean moray (Pereira et al. 2017). Movements for that species were $\sim 0.09 \mathrm{~km} / \mathrm{h}$ but were based on eel's regular activities, not during emigration as was calculated here.

Once at the backreef or farther offshore, detections ceased, a finding generally similar to a telemetry study of ontogenetic shifts in schoolmaster snapper (Lutjanus apodus) (Huijbers et al. 2015). The submarine canyon off Salt River Bay has a flat, sandy bottom that is flanked by two nearly vertical walls of rock and coral with countless overhangs, small caves, and crevices (Rogers et al. 1984; Kendall et al. 2005). This habitat is ideal for adult moray eels and provides abundant shelter and opportunities for concealed movement all along the reef structure. Eels may have remained in the canyon habitat after emigration, but were not detected once they established a new core area in such complex habitat. Moray eels are often observed with just their heads emerging from reef crevices and their body concealed, a behavior that would physically prevent detection of the transmitters which are inserted in the body cavity and would remain inside the reef structure (Bassett and Montgomery 2011). Emigrating eels may also have continued down the steep continuous slope of the canyon floor into deeper waters at the canyon mouth $(\sim 50 \mathrm{~m})$ or instead left the bays via the pavement on either side of the canyon then along the coastal reefs into adult habitats elsewhere around St.Croix.

Emigration events documented here appear to be permanent based on the available detection data and other evidence. None of the individuals were detected in the array again despite having more than enough battery life and up to 6 months of additional monitoring time after their departure until the array was decommissioned. These eels may have come back as older and larger individuals after the array was decommissioned, however, additional trapping observations suggest that this was unlikely. Eels larger than $99 \mathrm{~cm}$ were never caught in the small traps used to 
capture fish for this study (Kendall et al. 2021a) nor were they caught in much larger Antillean fish traps ( 50 by 150 by $200 \mathrm{~cm}$ traps with mesh size $3.8 \mathrm{~cm}$ ) that were used extensively during biannual sampling throughout these bays as part of a research project in the 2 years prior to this study (Kendall et al. 2021b). Only one large moray $>100 \mathrm{~cm}$ was ever captured inside the bays using these larger traps and it was next to a ship wreck in the central bay rather than associated with the mangroves (pers. obs.). These larger traps are effective for catching larger eels, in fact the largest eel in this study (126 cm TL) was trapped repeatedly in such a trap in a sand channel on hard bottom west of the canyon. Collectively, this suggests that larger eels are in much lower abundance in the bays and once the smaller eels leave the mangrove fringe, they do not return.

Eels suspected to be emigrating may instead have been eaten by a large predator such as a shark, which then left with the tag in their stomach (e.g., Gibson et al. 2015; Kahn et al. 2016). This however, seems unlikely since a predator large enough to eat a $1 \mathrm{~m}$ long eel that is swimming out in the open would be detected more frequently than an eel slinking along the bottom on its way out of the bays as our detection patterns demonstrated. Also, two eels showed pre-emigration movements the night before departure, returned to their core area, and then somewhat retraced their pre-emigration movements when completely departing. We do not believe that a predator would display this type of movement behavior for only two nights in a row and then never be detected in the bays again. These preemigration movements may be similar to exploration behaviors observed for some schoolmaster snapper prior to their final migration from mangroves to reefs (Huijbers et al. 2015).

Determining what triggers the ontogenetic habitat shift remains unknown. As has been shown for some other mangrove and reef fish (Aburto-Oropeza et al. 2009; Luo et al. 2009), there may be a seasonal influence since all of the eel emigration events occurred over several months during winter and spring. There was no clear lunar trigger as eels emigrated in any moon phase. On a diel timescale, eels waited until after dark to leave their core area (Huijbers et al. 2015) which could be to minimize risk from dayactive predators (Kahn et al. 2016) or may simply be due to the more nocturnally active tendency on the part of the eels.
Linking the ontogenetic shift of green moray eels to specific biological needs such as predation risk (Dahlgren and Eggleston 2000; Kimirei et al. 2013), maximizing growth (Dahlgren and Eggleston 2000; Kimirei et al. 2013), maturation (Cocheret de la Morinièr et al. 2003; Luo et al. 2009; Grol et al. 2014), diet change (Cocheret de la Morinièr et al., 2003), or food availability (Kimirei et al. 2013) as has been shown for some other reef fishes is difficult. This is partly due to the large gaps in understanding about even basic aspects of life history for nearly all moray eels including size at maturity, spawning season and location, growth rate, changes in prey size, and predation threats (Froese and Pauly 2020). Although emigrating eels were mostly larger than those that did not, maturity cannot be distinguished based on size, and the eels tracked here may still be subadults. Predation risk seems unlikely for green morays in any of its preferred habitats apart from conspecifics, as has been documented elsewhere in the genus Gymnothorax (Young and Winn 2003; Higgins and Mehta 2018). Another possibility is that as eels grow, they may move to take advantage of an increasing ability to consume larger prey items found on the reef compared to the mangroves which are dominated by smaller sized prey fish. For example, the California moray (G. mordax) shows mixed results of changing prey size with growth (Harrison et al. 2017; Higgins et al. 2018). However, it is not clear if California morays shift habitats as green morays appear to do, or if they essentially have the same size menu of prey as they grow.

The approach used here can be adapted to examine habitat shifts of fish in other systems. Although we documented several previously unknown aspects of green moray eel ecology, there are many more important questions to be investigated. Shelter hole fidelity and fine scale movements in mangrove bays are not understood. If any eels in the size class examined here $(\sim 50-100 \mathrm{~cm})$ are already offshore on reefs also unknown since we did not sample with the smaller mesh-sized traps in those habitats. Although mangroves and coral reefs are preferred habitats, green morays are not necessarily obligate users as they are occasionally reported off states northward along the US east coast lacking those habitats. Also of note, even younger and smaller eels were never caught in the mangroves in 2 years of trapping (Kendall et al. 2021a) despite the mesh 
size being fine enough to catch them. Perhaps, like many other reef fish species, smaller green morays initially recruit to and reside in seagrass habitats which would provide ideal camouflage for an animal the same general color and appearance as turtlegrass (Thalassia testudinum). As coral reefs continue to degrade, understanding the impact of reef flattening, the widespread loss of reef rugosity as corals die, bioerode, and physically break down, will also be important (Alvarez-Filip et al. 2009). This may reduce the three dimensional reef structure and sheltering opportunities required by eels (Abrams and Schein 1986) and may have especially dire consequences for Muraenidae in general.

Acknowledgements This project was conducted out of the Coastal Studies Outpost operated by the National Park Service (NPS). Field operations were supported by in-kind support from NPS, with special assistance provided by C. Pollock, N. Hanna Holloway, and Z. Hillis-Starr. Dock space was furnished by Salt River Bay Marina. A. Mason implemented dive operations. J.P. Oriol and L. Henderson provided conceptual guidance. R. Gosse, J. Pye, the Ocean Telemetry Network staff, B. Ahr, and J. Keller provided invaluable analytical assistance. A. Paxton, B. Williams, and T. Pait provided reviews of the draft manuscript. Some receivers were loaned from NOAA/NMFS and the US Caribbean Acoustic Network with thanks to J. Doerr, R. Hill, C. Pollock, and G. Skomal. This study is part of the FACT Network of telemetry research partners. Labor was provided by CSS Inc., under contract GS-00F-217CA / EA133C17BA0062.

Author contribution Conceptualization: Kendall, Monaco; methodology: Kendall, Siceloff, Winship; formal analysis and investigation: Kendall, Siceloff; writing-original draft preparation: Kendall, Siceloff; writing-review and editing: Kendall, Siceloff, Ruffo, Monaco; funding acquisition: Kendall, Monaco; resources: Ruffo; supervision: Kendall, Monaco.

Funding Funding was provided by NCCOS [Project 706] and NOAA's Coral Reef Conservation program [Project 31190].

Data availability Archived data is available through the Florida Atlantic Coast Telemetry Network and Ocean Tracking Network after 5-year embargo.

\section{Code availability N/A}

\section{Declarations}

Ethics approval Scientific research, collection, and animal care were approved under NPS [SARI-2018-SCI-0001] [SER_SARI_Kendall_Fish_2018], US Virgin Islands DPNR [CZM17040X], and NOAA National Environmental Policy Act protocols.

\section{Consent to participate N/A}

\section{Consent for publication N/A}

Conflict of interest The authors declare no competing interests.

Disclaimer The views and conclusions contained in this document are those of the authors and should not be interpreted as representing the opinions or policies of the US Government, nor does mention of trade names or commercial products constitute endorsement or recommendation for use.

Open Access This article is licensed under a Creative Commons Attribution 4.0 International License, which permits use, sharing, adaptation, distribution and reproduction in any medium or format, as long as you give appropriate credit to the original author(s) and the source, provide a link to the Creative Commons licence, and indicate if changes were made. The images or other third party material in this article are included in the article's Creative Commons licence, unless indicated otherwise in a credit line to the material. If material is not included in the article's Creative Commons licence and your intended use is not permitted by statutory regulation or exceeds the permitted use, you will need to obtain permission directly from the copyright holder. To view a copy of this licence, visit http://creativecommons.org/licenses/by/4.0/.

\section{References}

Abrams RW, Schein MW (1986) Individual movements and population density estimates for moray eels on a Caribbean coral reef. Coral Reefs 5:161-163. https://doi.org/10. 1007/BF00298183

Abrams RW, Abrams MD, Schein MW (1983) Diurnal observations on the behavioral ecology of Gymnothorax moringa (Cuvier) and Muraena miliaris (Kaup) on a Caribbean coral reef. Coral Reefs 1:185-192. https://doi.org/10. 1007/BF00571196

Aburto-Oropeza O, Dominguez-Guerrero I, Cota-Nieto J, Plomozo-Lugo T (2009) Recruitment and ontogenetic habitat shifts of the yellow snapper (Lutjanus argentiventris) in the Gulf of California. Mar Biol 156:2461-2472. https:// doi.org/10.1007/s00227-009-1271-5

Alvarez-Filip L, Dulvy NK, Gill JA, Côté IM, Watkinson AR (2009) Flattening of Caribbean coral reefs: regionwide declines in architectural complexity. Proc R Soc B 276:3019-3025. https://doi.org/10.1098/rspb.2009.0339

Aschenbrenner A, Marques S (2018) First record of foraging association between juveniles of endemic Brazilian snapper (Lutjanus alexandrei) and green moray at mangrove prop roots in the southwestern Atlantic. Mar Biodiv 48:1275-1276. https://doi.org/10.1007/ s12526-016-0579-x

Bassett D, Montgomery J (2011) Home range use and movement patterns of the yellow moray eel Gymnothorax 
prasinus. J Fish Biol 79:520-525. https://doi.org/10. 1111/j.1095-8649.2011.03018.x

Calenge C (2006) The package "adehabitat" for the R software: a tool for the analysis of space and habitat use by animals. Ecological Mod 197:516-519. https://doi.org/10.1016/j. ecolmodel.2006.03.017

Campbell HA, Watts ME, Dwyer RG, Franklin CE (2012) V-Track: software for analysing and visualizing animal movement from acoustic telemetry detections. Mar Freshwater Res 63(9):815-820. https://doi.org/10.1071/MF121 94

Chan TYK (2017) Regional variations in the risk and severity of ciguatera caused by eating moray eels. Toxins 9(7):201. https://doi.org/10.3390/toxins9070201

Cocheret de la Morinière E, Pollux BJA, Nagelkerken I, van der Velde G (2003) Diet shifts of Caribbean grunts (Haemulidae) and snappers (Lujanidae) and the relation with nursery-to-coral reef migrations. Est Coast Shelf Sci 57:1079-1089. https://doi.org/10.1016/S0272-7714(03) 00011-8

Dahlgren C, Eggleston D (2000) Ecological processes underlying ontogenetic habitat shifts in a coral reef fish. Ecol 81(8):2227-2240. https://doi.org/10.1890/00129658(2000)081[2227:EPUOHS]2.0.CO;2

Froese R, Pauly D (Eds) (2020) FishBase. World Wide Web electronic publication. www.fishbase.org, version $(12 / 2020)$

Gibson AJF, Halfyard EA, Bradford RG, Stokesbury MJW, Redden AM (2015) Effects of predation on telemetry-based survival estimates: insights from a study on endangered Atlantic salmon smolts. Can J Fish Aq Sci 72(5):728-741. https://doi.org/10.1139/cjfas-2014-0245

Gilbert M, Rasmussen JB, Kramer DL (2005) Estimating the density and biomass of moray eels (Muraenidae) using a modified visual census method for hole-dwelling reef fauna. Env Biol Fish 73:415-426. https://doi.org/10.1007/ s10641-005-2228-2

Grol MGG, Rypel AL, Nagelkerken I (2014) Growth potential and predation risk drive ontogenetic shifts among nursery habitats in a coral reef fish. Mar Ecol Prog Ser 502:229244. https://doi.org/10.3354/meps10682

Harrison JS, Higgins BA, Mehta RS (2017) Scaling of dentition and prey size in the California moray. Zoology 122:16-26. https://doi.org/10.1016/j.zool.2017.02.002

Higgins BA, Mehta RS (2018) Distribution and habitat associations of the California moray (Gymnothorax mordax) within Two Harbors, Santa Catalina Island, California. Env Biol Fish 101:95-108. https://doi.org/10.1007/ s10641-017-0684-0

Higgins BA, Law CJ, Mehta RS (2018) Eat whole and less often: ontogenetic shoft reveals size specialization on kelp bass by the California moray eel, Gymnothorax mordax. Oecologia 188:875-887. https://doi.org/10.1007/ s00442-018-4260-x

Hixon MA, Beets JP (1993) Predation, prey refuges, and the structure of coral-reef fish assemblages. Ecol Mon 63(1):77-101. https://doi.org/10.2307/2937124

Huijbers CM, Nagelkerken I, Layman CA (2015) Fish movement from nursery bays to coral reefs: a matter of size?
Hydrobiologia 750:89-101. https://doi.org/10.1007/ s10750-014-2162-4

Kahn JA, Welsh JQ, Bellwood DR (2016) Using passive acoustic telemetry to infer mortality events in adult herbivorous coral reef fishes. Coral Reefs 35:411-420. https://doi.org/ 10.1007/s00338-015-1387-7

Kendall MS, Takata LT, Jensen O, Hillis-Starr Z, Monaco ME (2005) An ecological characterization of the Salt River Bay National Historical Park and Ecological Preserve, U.S. Virgin islands. NOAA Technical Memorandum NOS NCCOS 14. Silver Spring, Maryland USA. 116

Kendall MS, Williams B, Ruffo A, Winship A, Siceloff L, Adams A, Tobias W (2021a) Resampling 25 years later reveals fewer species but higher abundance of juvenile fishes in a Caribbean mangrove bay. Bull Mar Sci 97(1):53-74. https://doi.org/10.5343/bms.2020.0005

Kendall MS, Siceloff L, Monaco ME, Ruffo A, Winship AJ, Hanna Holloway N (2021) Measuring mutual movements, mixing, and mingling among multiple mangrove bays by an important estuarine sea bream (Archosargus rhomboidalis). Est Coast Shelf Sci 252:107254. https://doi.org/10. 1016/j.ecss.2021.107254

Kimirei IA, Nagelkerken I, Trommelen M, Blankers P, van Hoytema N, Hoeijmakers D, Huijbers CM, Mgaya YD, Rypel AL (2013) What drives ontogenetic niche shifts of fishes in coral reef ecosystems? Ecosystems 16:783-796. https://doi.org/10.1007/s10021-013-9645-4

Krueger CC, Holbrook CM, Binder TR, Vandergoot CS, Hayden TA, Hondorp DW et al (2017) Acoustic telemetry observation systems: challenges encountered and overcome in the Laurentian Great Lakes. Can J Fish Aquat Sci 75:1755-1763. https://doi.org/10.1139/cjfas-2017-0406

Luo J, Serafy JE, Sponaugle S, Teare PB, Kieckbusch D (2009) Movement of gray snapper Lutjanus griseus among subtropical seagrass, mangrove, and coral reef habitats. Mar Ecol Prog Ser 380:255-269. https://doi.org/10.3354/ meps07911

Mehta RS, Wainwright PC (2008) Functional morphology of the pharyngeal jaw apparatus in moray eels. J Morph 269(5):604-619. https://doi.org/10.1002/jmor.10612

Parrish JD, Norris JE, Callahan MW, Callahan JK, Magarifuji EJ, Schroeder RE (1986) Piscivory in a coral reef fish community. In: Simenstad CA, Cailliet GM (eds) Contemporary studies on fish feeding: the proceedings of GUTSHOP '84. Developments in environmental biology of fishes, vol 7. Springer, Dordrecht. https://doi.org/10.1007/ 978-94-017-1158-6_24

Pereira TJ, Silva AF, Raposo de Almeida P, Belo AF, Costa JL, Castro N, Quintella BR (2017) Assessing the size adequancy of a small no-take marine protected area (MPA) for Mediterranean moray and European conger. Mar Ecol Prog Ser 584:213-277. https://doi.org/10.3354/meps1 2379

Randall JE (1967) Food habits of reef fishes of the West Indies. Stud Trop Oceanogr 5:665-847

Robins CR, Ray GC (1986) A field guide to Atlantic coast fishes of North America. Houghton Mifflin Company, Boston, p 354 
Rogers CS, Fitz HC III, Gilnack M, Beets J, Hardin J (1984) Scleractinian coral recruitment patterns at Salt River Submarine Canyon, St. Croix. US Virgin Islands Coral Reefs 3:68-76

Santos FB, Castro RMC (2003) Activity, habitat utilization, feeding behaviour, and diet of the sand moray Gymnothorax ocellatus (Anguilliformes, Muraenidae) in the south western Atlantic. Biota Neotrop 3(1):1-7

Simpfendorfer CA, Heupel MR, Hueter RE (2002) Estimation of short-term centers of activity from an array of omnidirectional hydrophones and its use in studying animal movements. Can J Fish Aquat Sci 59(1):23-32. https:// doi.org/10.1139/f01-191

Swadling D, Knott N, Rees M, Pederson H, Adams K, Taylor M, Davis A (2020) Seagrass canopies and the performance of acoustic telemetry: implications for the interpretation of fish movements. Animal Biotelemetry. 8:8. https://doi.org/10.1186/s40317-020-00197-w
Vail AL, Manica A, Bshary R (2013) Referential gestures in fish collaborative hunting. Nat Commun 4(1):1765. https://doi.org/10.1038/ncomms2781

Young RF, Winn HE (2003) Activity patterns, diet, and shelter site use for two species of moray eels, Gymnothorax moringa and Gymnothorax vicinus, in Belize. Copeia 1:44-55

Young JM, Bowers ME, Reyier EA, Morley D, Ault ER, Pye JD, Gallagher RM, Ellis RD (2020) The FACT Network: philosophy, evolution, and management of a grassroots collaborative coastal tracking network. Mar Coastal Fish 12(5):258-271. https://doi.org/10.1002/mcf2.10100

Zar JH (1999) Biostatistical analysis, 4th edn. Prentice-Hall Inc., Upper Saddle River

Publisher's note Springer Nature remains neutral with regard to jurisdictional claims in published maps and institutional affiliations. 